\title{
CDISC SDTM Pharmaceutical Dosage Form Terminology
}

National Cancer Institute

\section{Source}

National Cancer Institute. CDISC SDTM Pharmaceutical Dosage Form Terminology. NCI Thesaurus. Code C66726.

Terminology codelist used with Pharmaceutical Dosage Form within the Clinical Data Interchange Standards Consortium Study Data Tabulation Model. 